Cell Research (2000), 10, 115--125

\title{
The expression of glucose regulated protein-94 in colorectal carcinoma cells treated by sodium butyrate
}

\author{
Wu Yi Di, Jin Dan Song* \\ Key Laboratory of Cell Biology, Ministry of Public Health of \\ China \\ Institute of Medical Molecular Biology, China Medical University, \\ 92 Beier Rd. Heping District, Shenyang 110001, China
}

\begin{abstract}
The expression of glucose regulated protein 94 (GRP94) during the treatment of human colorectal carcinoma cell lineClone A cells with sodium butyrate was studied. Sodium butyrate (SB) can cause functional and morphological effects on Clone A cells including growth arrest at $\mathrm{G}_{0} / \mathrm{G}_{1}$ stage and cell differentiation as observed by morphological changes, MTT and flow cytometry assays, as well as reduced Grp94 gene expression as shown by Northern blot and Western blot assays. The possible mechanism of the correlation between Grp94 gene expression and tumor growth inhibition and cell differentiation is briefly discussed.
\end{abstract}

Key words: HSPs, Grp94, sodium butyrate, colorectal carcinoma cells.

\section{INTRODUCTION}

The stress proteins are the products of a very highly conserved genetic system in the cells. In mammalian cells, this system is divided into two predominant categories which appear to be structurally and functionally related: the heat shock proteins (HSPs) and the glucose-regulated proteins (GRPs). These protein sets, however, are separable basing on their differential sensitivity to different kinds of stresses[1],[2].

Heat shock proteins (HSPs) is a group of highly conserved proteins synthesized after heat induction. The most prominent HSPs of mammalian cells have molecular weights of approximately 90,000 (HSP90), and 70,000 (HSP70)[1],[3]. Many studies have suggested a possible correlation between the expression of HSPs and the growth and differentiation

\footnotetext{
* Corresponding author: Fax: (024)23256087; E-mail: jdsong@sun10.cmu.edu.cn
} 
Grp94 expression in colorectal carcinoma cells

of tumor cells[4-9]. Recent evidence revealed that considerable expression of HSPs is found in non-heat-shocked cells, showing that HSPs may be induced by other stresses and participated in broader body defense and even in normal growth and development[10]. GRPs was also induced by various stresses to function as molecular chaperones[11],[12]. Enhanced expression of GRPs during the growth of cancer cells imply its close relationship with the cell growth[13]. However, few reports have studied the expression of Grps genes especially during the course of tumor growth and differentiation in comparison with those of HSPs. GRP94, an ER molecular chaperone sharing high identity with HSP90, belongs to Hsp90 gene family and participates in many important biological process as molecular chaperone[14].

Sodium butyrate (SB) has been shown to inhibit the growth and induce differentiation and apoptosis of colorectal carcinoma cells[15]. However, the molecular mechanisms that underlie butyrate-mediated growth arrest have not been fully elucidated. Therefore, we think it is worthy to investigate the Grp94 gene expression and its possible mechanism during the treatment with sodium butyrate on colorectal carcinoma Clone A cells.

\section{MATERIALS AND METHODS}

\section{Cell culture and cell treatment}

The human colonic carcinoma Clone A cell line was a generous gift of Dana-farber Cancer Institute, Harvard Medical School, USA. Clone A cells were maintained in Dulbecco' s Modified Eagle' s medium supplemented with $10 \%$ calf serum and cultured at $37^{\circ} \mathrm{C}$ in humidified atmosphere containing $5 \% \mathrm{CO}_{2}$. Clone A cells at exponential growth stage were subcultured and randomly allocated into experimental group and control group. The experimental group was added with SB dissolved in distilled water to a final concentration of $2 \mathrm{~m} \mathrm{M}$ and $4 \mathrm{~m} \mathrm{M}$ for $2 \mathrm{~d}$ and $4 \mathrm{~d}$ respectively, and the control group was added with the same amount of distilled water.

\section{Observation on morphological changes of Clone A cells using LM, $S E M$ and TEM}

Clone A cells were treated with SB for $4 \mathrm{~d}$ and the morphological changes were observed with conventional Phase-Contrast Microscopy, Scanning Electron Microscopy (SEM) and Transmission Electron Microscopy (TEM).

\section{MTT assay}

The effect of SB on Clone A cells were measured by MTT assay. Briefly, $5 \times 10^{4} / \mathrm{ml}$ cells were inoculated onto a 96-well plates in $100 \mu \mathrm{l}$ regular medium per well and after $24 \mathrm{~h}$ culture, the cells of each well were exposed to SB to a final concentration of $2 \mathrm{~m} \mathrm{M}$ and $4 \mathrm{~m} \mathrm{M}$ for $2 \mathrm{~d}$ and $4 \mathrm{~d}$ respectively. At the end of the exposure, $10 \mu \mathrm{l}(5 \mathrm{mg} / \mathrm{ml})$ MTT in PBS was then added. After inoculation for $4 \mathrm{~h}$ at $37^{\circ} \mathrm{C}$, the supernatant was removed and precipitated formazan crystals were dissolved in $100 \mu \mathrm{l}$ DMSO and the plates were shaken for $2 \mathrm{~min}$. Ten min later, the cells survival rate was determined by measuring the value of OD540 with an ELISA reader (Bio-TEK Instruments Inc).

\section{Flow-cytometric analysis}

$5 \mathrm{ml}$ exponentially grown Clone A cells $\left(5 \times 10^{5} / \mathrm{ml}\right)$ were plated in $25 \mathrm{~cm}^{2}$ plastic flasks and 
randomly divided into experimental group and control group with 3 parallel samples in each group. After $24 \mathrm{~h}$, cells were treated with $2 \mathrm{~m} \mathrm{M} \mathrm{SB}$ for $2 \mathrm{~d}$ or $4 \mathrm{~d}$. Cells were trypsinized, washed once with PBS and fixed in $1 \mathrm{ml}$ ice-cold $70 \%$ ethanol for $1 \mathrm{~h}$ at $4{ }^{\circ} \mathrm{C}$. Fixed cells were pelleted, resuspended in $0.5 \mathrm{ml}$ PBS containing $200 \mathrm{ng} / \mathrm{ml} \mathrm{RNase} \mathrm{A} \mathrm{at} 37^{\circ} \mathrm{C}$ for $30 \mathrm{~min}$ and stained with propidium iodide (PI, Sigma). FACS flow cytometer fluorescence intensity was measured by FACScan flow-cytometer and the DNA content in cells was analyzed by Modfit software.

\section{Northern blot analysis}

Total RNA was prepared using TRIZOL RNA extraction kit (Gibco BRL product) from cultured Clone A cells. From each sample, $30 \mu \mathrm{g}$ RNA was electrophoresed through a $1.5 \%$ formaldehydeagarose gel, then transferred to a nylon filter. The membranes were hybridized with Grp94 cDNA inserts labeled with ${ }^{32} \mathrm{P}$-dCTP by the random primer method at $68^{\circ} \mathrm{C}$ for $14-16 \mathrm{~h}$. The blots were then washed at high stringency and exposed to X-ray film at $-80{ }^{\circ} \mathrm{C}$ using an intensifying screen.

\section{Specificity of anti-GRP94 antibody and Western blot assay}

Rat monoclonal antibody specific forGRP94 (Affinity Bioreagents Inc.) was used at a dilution of 1:2000 in Western blot assay. This GRP94 antibody is of IgG $2 \alpha$ class and was prepared by immunizing rats with purified immunogen from chicken oviducts. We confirmed the specificity of this antibody in Clone A cells using Western blot analysis. Proteins from Clone A cells were separated on a $7.5 \%$ SDS polyacrylamide gel and transferred to nitrocellulose. The membranes were exposed to a rat monoclonal antibody against GRP94 or without GRP94 antibody. In addition, since GRP94 shares considerable homology to Hsp90, we checked for cross-reactivity of the GRP94 antibody with purified human liver HSP90 protein and the result was negative.

\section{Western blotting analysis}

Whole cells from treated and untreated Clone A cells were washed once in PBS and the cells were harvested from flasks by a rubber policeman. The cells were resuspended in $500 \mu l$ buffer, ( $2 \mathrm{mM}$ EDTA, $10 \mathrm{mM}$ EGTA, $20 \mu \mathrm{M}$ Tris. $\mathrm{HCl} \mathrm{pH} \mathrm{7.5,} 1 \mathrm{~m}$ M Phenylmthylsufonyl floride), then sonicated and centrifuged at $100,000 \times$ at $4^{\circ} \mathrm{C}$ for $1 \mathrm{~h}$. The supernatants were harvested and assayed for protein concentration by the Folin-Lowry method. $100 \mu$ g protein of each sample was denatured in SDS sample buffer and run in a $7.5 \%$ polyacrylamide gel together with high molecular mass standards (Sigma). Proteins separated by SDS-PAGE were then electrophoretically blotted onto nitrocellulose membranes. The membrane was blocked by $5 \%$ gelatin in Trisbuffered saline (TBS) for $1 \mathrm{~h}$ at room temperature and subsequently incubated with antibody for GRP94 (1:2000 dilution) over night. The membrane was washed with TBS to remove unbound antibody and incubated with second anti-rat immunoglobin conjugated with alkaline phosphatase. Bands were visualized with the use of alkaline phosphatase detection reagent $(100 \mathrm{ml}$ stock solution: $2.3 \% \mathrm{Na} 2 \mathrm{~B} 4 \mathrm{O} 7.10 \mathrm{H}_{2} \mathrm{O}, 0.12 \% \mathrm{MgSO}_{4} \cdot 7 \mathrm{H}_{2} \mathrm{O}, \mathrm{pH} 9.7,25 \mathrm{mg}$ Tetrazotized O-dianisidine, $25 \mathrm{mg} \beta 4$-naphthyl acid phosphate) (Sigma). The density of stained bands were quantified with an image analyzer (GDS 800, UVP product).

\section{RESULTS}

\section{Effect of sodium butyrate on the morphology of Clone A cells}

Clone A cells usually assumed an irregular or rhomboid shape, but they turned into long fibroblast-like appearance after treating with SB. The morphological changes of Clone A cells were visible in $2 \mathrm{~d}$ after treatment and become obvious and typical $4 \mathrm{~d}$ after 


\section{Grp94 expression in colorectal carcinoma cells}

SB treatment (Fig 1A, B). By SEM, the control cells displayed a relatively smooth cell surface, while the treated cells grew more and longer filopodia on cell surface in $4 \mathrm{~d}$ as shown in Fig 1C, D. Under TEM, Clone A cells had large and irregular nucleus with at least two nucleoli and some with nuclear membrane invagination. After SB treatment, the nucleus became small and regular and nucleocytoplasmic ratio was decreased accordingly. TEM also showed that Clone A cells had fewer cytoplasm and relatively less amount of organelles, such as ER with vesicle dilation, Golgi apparatus and mitochondria etc., while in the SB-treated Clone A cells, there were relatively more cytoplasm and increased quantity of organelles. ER increased in amount and became more complex in structure, distributing around nucleus and extending through the cytoplasm. And also more Golgi apparatus and mitochondria could be seen in the cytoplasm (Fig 1E, F).
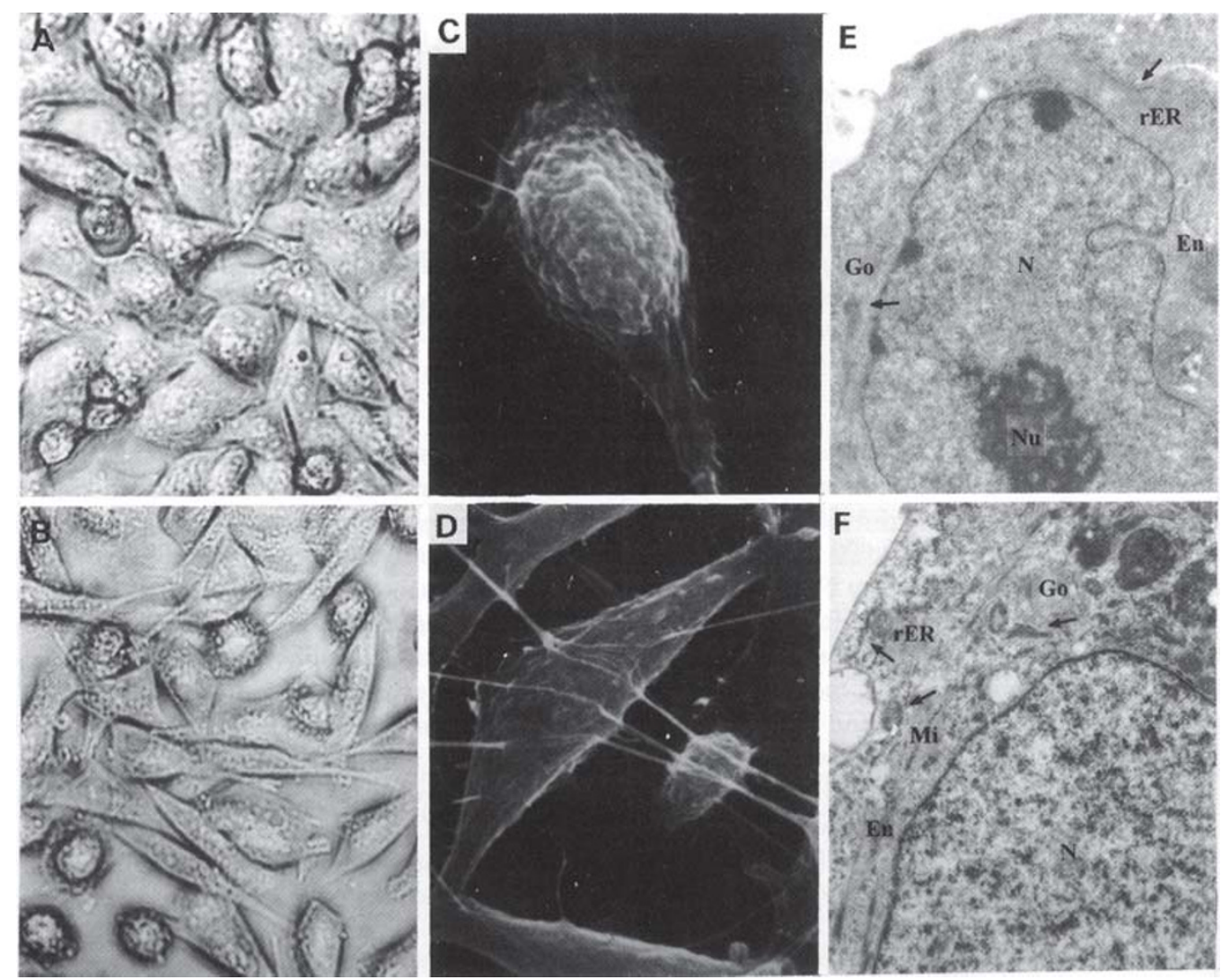

Fig 1.

Effect of sodium butyrate on the morphology of Clone A cells

A, C, E represent the morphology of control Clone A cells under the LM $(200 \times)$, SEM (4000 $\times)$ and TEM $(10,000 \times)$ respectively. B, D, F represent morphological changes of Clone A cells treated with SB for $4 \mathrm{~d}$ under similar conditions.

$\mathrm{N}$ : nucleus; Nu: nucleoli; En: envelope; rER: rough endoplasm reticulum; Go: Golgi apparatus; Mi: mitochondria 
Wu YD, JD Song

\section{Effect of sodium butyrate on Clone A cells survival by MTT assay}

After being treated with SB in different doses ( $2 \mathrm{~m} \mathrm{M}$ and $4 \mathrm{mM}$ ) for $2 \mathrm{~d}$ and $4 \mathrm{~d}$ respectively, MTT assay was used to measure the effect of SB on Clone A cells survival. It was found that growth of Clone A cells was obviously inhibited in the presence of SB, with $50 \%$ inhibition at the concentration of $2 \mathrm{mM}$ and $70 \%$ at $4 \mathrm{~m} \mathrm{M}$, in dose-and timedependent manner as shown in Fig 2.

Fig 2.

Effects of sodium butyrate on Clone A survival by MTT assay. The experiment was repeated three times with similar results. Each point represents the mean of results $(-\triangleright-2 \mathrm{~m} M,-\square-4 \mathrm{~m} M$ ).

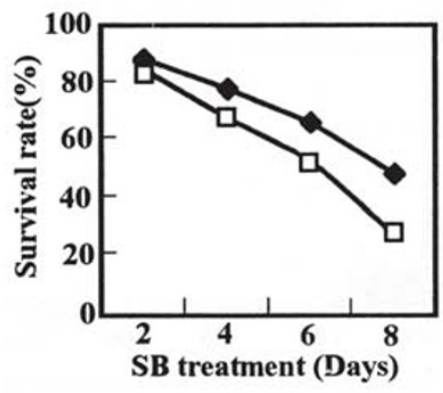

The effect of sodium butyrate on the growth of Clone A cells and the cell cycles

In order to understand the effect of sodium butyrate on the growth of Clone A cells, flow cytometric analysis of PI stained cells was performed. Fig 3 and Tab 1 showed that the treatment of Clone A cells with a $2 \mathrm{mM} \mathrm{SB}$ for $2 \mathrm{~d}$ and $4 \mathrm{~d}$ resulted in a consistent increase in the fraction of cells in $\mathrm{G}_{1}$ phase and decrease in $\mathrm{S}$ phase as compared to untreated Clone A cells.

Tab 1. DNA content analysis of Clone A treated with SB

\begin{tabular}{cccccc}
\hline \multirow{2}{*}{$\begin{array}{c}\text { Time } \\
\text { (days) }\end{array}$} & $\begin{array}{c}\text { SB concentration } \\
\mathrm{mM}\end{array}$ & \multicolumn{2}{c}{ Percentage of tumor cells at cell cycles } & \multirow{2}{*}{$\mathrm{PI}(\%)$} \\
\cline { 2 - 5 } & $\mathrm{G}_{0} / \mathrm{G}_{1}$ & $\mathrm{~S}$ & $\mathrm{G}_{2} / \mathrm{M}$ & \\
\hline 2 & 0 & 55.61 & 35.04 & 9.35 & 44.39 \\
& 2 & 61.14 & 30.39 & 8.47 & 38.86 \\
\hline 4 & 0 & 55.73 & 36.87 & 7.40 & 44.27 \\
& 2 & 67.36 & 13.61 & 19.04 & 32.68 \\
\hline
\end{tabular}

PI represents Proliferation Index, $P I=\frac{S+G_{2} / M}{G_{0} / G_{1}+S+G_{2} / M}$

\section{Effect of sodium butyrate on Grp94 gene expression}

For the study of Grp 94 gene expression, a 270 bp product was amplified by RT-PCR with Grp94 specific primers and cloned into TA vector. The cDNA fragment was confirmed as Grp94 after DNA sequencing and analogue analyzing. At the same time, $\beta$-actin was used as an internal control and its $534 \mathrm{bp}$ RT-PCR product was also amplified (data not shown). The effect of $2 \mathrm{~m} \mathrm{M} \mathrm{SB}$ on the expression of Grp94 was studied at the mRNA and protein levels. Northern blot analysis revealed that the amount of Grp94 mRNA was much higher 
Grp94 expression in colorectal carcinoma cells

in untreated Clone A cells. After the treatment with SB, Grp94 mRNA decreased markedly with time (Fig 4). In Western blot analysis of Grp94 expression, only one band at approximately $94 \mathrm{KDa}$ was identified. Clone A cells contained more GRP94 protein than that treated with SB (Fig 5), a result consistent with its change of Grp 94 mRNA level. The bands were quantified by densitometry.
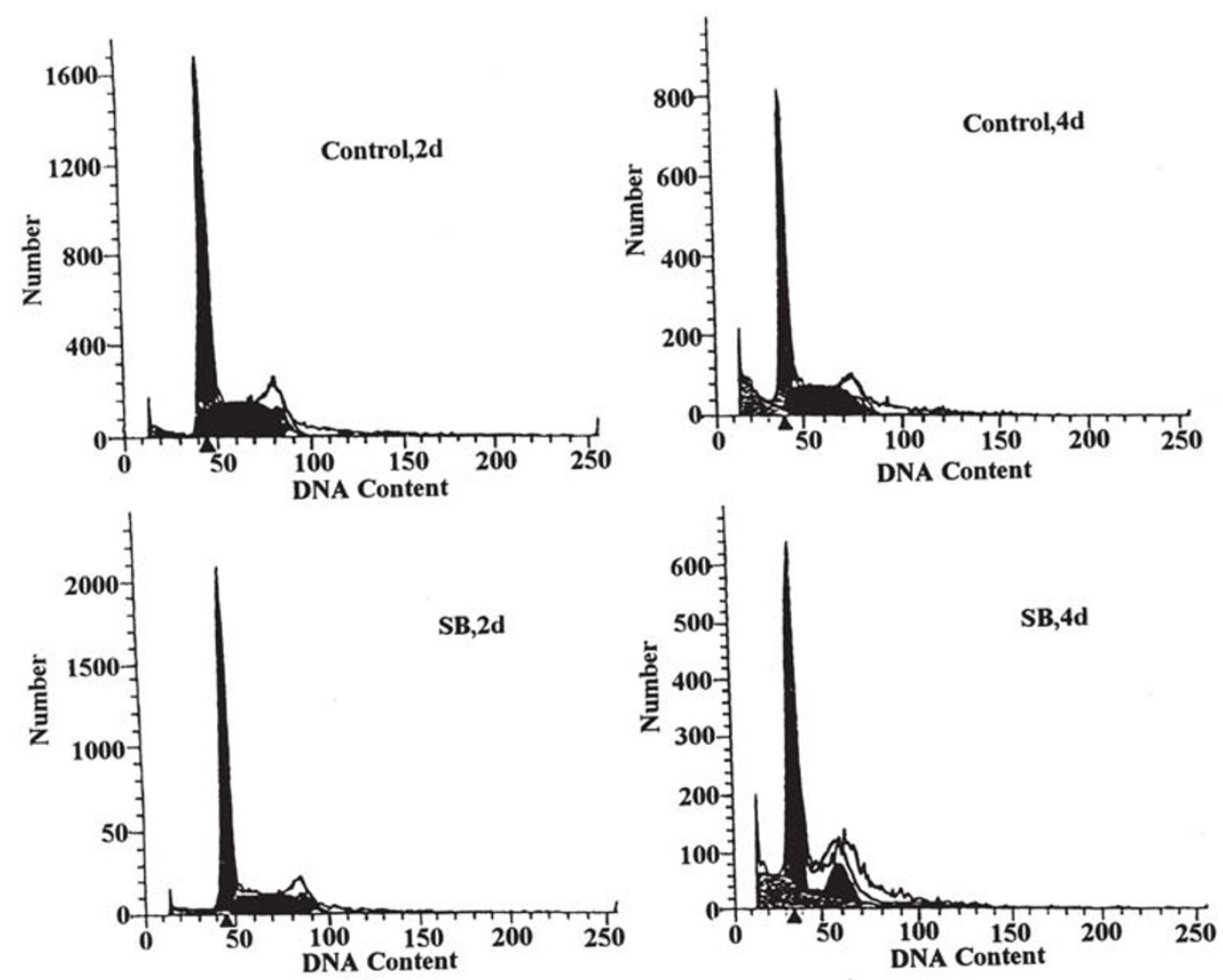

Fig 3.

Flow cytometric analysis of growth inhibition of Clone A cells in $G_{1}$ phase following exposure to $2 \mathrm{mM} \mathrm{SB}$ for $2 \mathrm{~d}$ and $4 \mathrm{~d}$. The experiment was repeated three times with similar results.

\section{$\triangleright$ Fig 5 .}

Western blot assay to detect GRP94 protein with specific rat monoclonal antibody against GRP94 in Clone A cells after the treatment with SB.

Clone A cells were treated with SB for $2 \mathrm{~d}$ and for $4 \mathrm{~d}$. $100 \mu \mathrm{g}$ of extracted proteins were loaded and run in $7.5 \%$ SDS-polyacrylamide gels and later transferred to nitrocellulose membranes, which were probed with anti-GRP94 antibody. A: Detection of specificity of GRP94 antibody by Western blots. A single band at approximately $94 \mathrm{KDa}$ was identified in lane 1 and no band was found without exposing to antibody against GRP94 (lane 2). B: Western blots of Clone A cells treated with SB, showing the reduction of GRP94 protein content. C: The densitometric analysis of the data presented in B, indicating that the decrease of GRP94 protein upon SB treatment is parallel to that of Grp94 mRNA as shown in Fig 4. 
Wu YD, JD Song

A

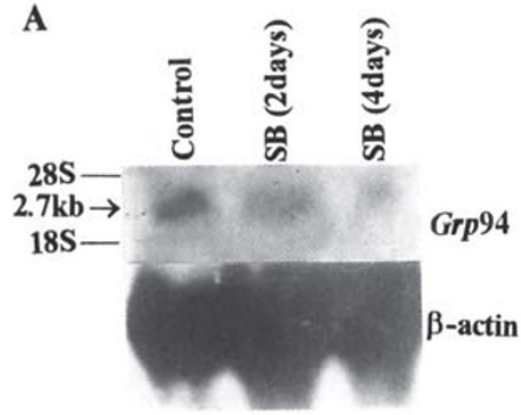

B

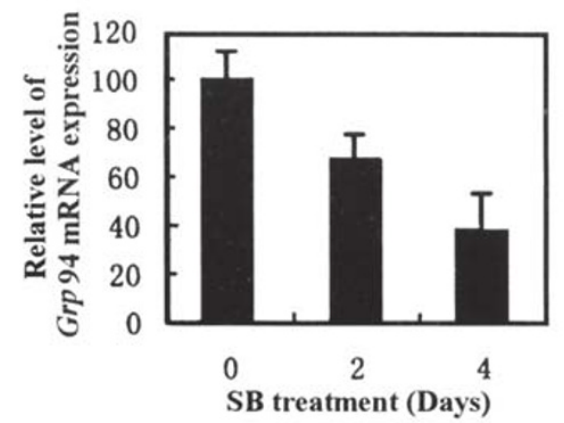

Fig 4.

Effect of sodium butyrate on Grp94 expression in Clone A cells by Northern blot analysis. $30 \mu \mathrm{g}$ total RNA were separated by $1.5 \%$ agarose gel electrophoresis, and Northern blot was performed using Grp 94 cDNA probe and $\beta$-actin probe labeled with ${ }^{32} \mathrm{P}$-dCTP by the random primer method.

A: Each lane was loaded with $30 \mu \mathrm{g}$ total RNA of Clone A cells. From left to right, lane 1 without SB treatment, lane 2, 3 treated with SB for 2 and for $4 \mathrm{~d}$ respectively. The size of hybridization band was approximately deduced by comparing the distance from loading well to the band of $28 \mathrm{~S}$ rRNA $(6.3 \mathrm{~kb})$ and $18 \mathrm{~S}$ rRNA $(2.3 \mathrm{~kb})$ with that from hybridization band to loading well. The positions of the $28 \mathrm{~S}$ and $18 \mathrm{~S}$ ribosomal RNAs are indicated at the margins.

B: The amount of mRNA were grossly quantified by densitometry and represented as percentage change of Grp94 expression with control cells arbitrarily taken as $100 \%$, mean $\pm S D$ ( $n \geqslant 3$ in all cases).

A

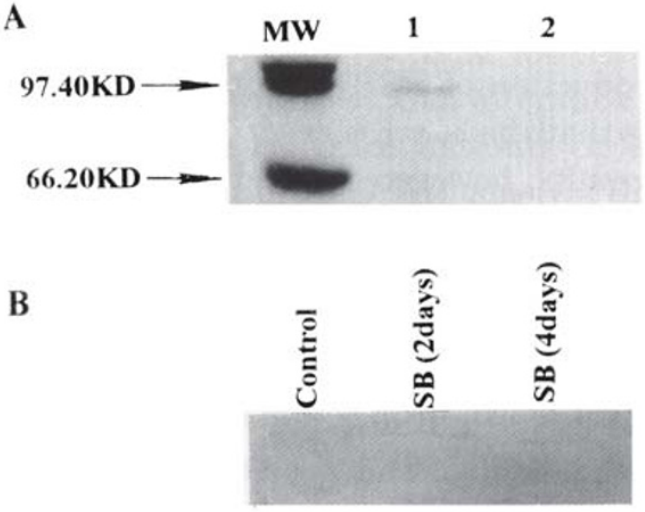

C

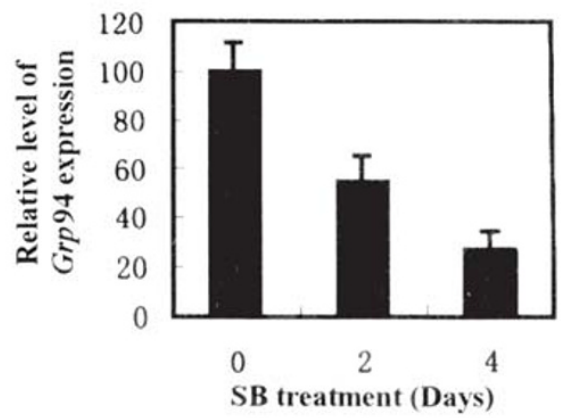


Grp94 expression in colorectal carcinoma cells

\section{DISCUSSION}

In the present paper, we studied the effect of sodium butyrate on poorly differentiated human colorectal carcinoma Clone A cells. The results indicated that the growth of Clone A cells is obviously inhibited and cells are arrested at $G_{0} / G_{1}$ phase of cell cycle after $S B$ treatment, a fact which could be considered as an early event in cell differentiation. The morphological change of Clone A cells from irregular and rhomboid shape to a long fibroblast-like appearance was consistent with results found in the previous report[16]. The organelles, such as ER, Golgi apparatus and mitochondria increased in amount and became more complex in structure after SB treatment. These results provided evidence that SB could induce the differentiation of Clone A cells and lead to their structural alterations[17],[18].

With respect to the expression of Grp94 gene in Clone A cells under this condition, it was found that considerable level of Grp 94 mRNA is present in the Clone A cells as shown by Northern blot analysis, but the amount of mRNA reduces drastically in a time-dependent manner after the treatment with SB. The change of the amount of protein encoded by Grp 94 gene is also consistent with the change of its mRNA level as shown in Western blot analysis. In connection with the changes of Grp94 gene expression of colorectal carcinoma cells upon SB tratment, it is interesting to note that several studies have suggested that HSPs play some roles during cell growth and cell differentiation of tumor. The expression of the Hsp90 gene was enhanced in the leukemia cell lines and the acute leukemia cells as compared with normal mononuclear cells, but was markedly suppressed after tumor growth inhibition[5]. Continuous expression of HSPs proteins in tumor cells may be required to serve as molecular chaperones in regulating and stabilizing tumor growth process. Several studies also revealed that some Hsps gene(s) were activated by differentiation inducer, suggesting their roles during differentiation of tumor cells[8], [9]. For instance, an increase in the mRNA or protein expression of $H s p 70$ gene was shown during the differentiation of human leukemic cells to erythrocytes, monocytes or macrophages and the inhibition in the production of HSP70 protein could reduce the accumulation of hemoglobin, indicating that the latter is needed for full differentiation capability of K562 cells[8]. Other results, however, implied that some HSPs are not strictly required for differentiation in spite of their high level in differentiated tumor cells[19]. All these findings have no satisfactory explanation yet. It is not entirely clear whether agent that induce differentiation may also induces a stress response or if differentiation process per se involves the induction of HSPs.

GRPs, sharing highly in amino acid identity to HSPs, are thought to act as molecular chaperone, helping in transporting, folding and processing of their target proteins. The Grp78 and Grp94 are members of the Hsp70 and Hsp90 gene family respectively, and available evidence indicates that members of each family express analogous functions and physico-chemical characteristics. However, GRPs do differ from the HSPs proteins which are localized in cytoplasm and mitochondria, whereas, GRPs are mostly located in 
$\mathrm{Wu}$ YD, JD Song

endoplasmic reticulum and nuclear envelope. Furthermore, GRP94 has also been identified as a murine tumor rejection antigen, indicating that to some extent it can also reside on the cell surface[20]. It has been shown that large amount of GRPs proteins were synthesized during tumor growth, HSP90 protein, in this case, was repressed[13]. The possible explanation might be that GRPs proteins is likely to be triggered by abnormalities in protein processing or folding in the endoplasmic reticulum, which, in some cases, has been shown to be resulted from abnormal glycosylation. Although the cellular implication of the increased production of these proteins is unknown, it may be expected that each response would enhance the capacity of the pathway(s) in which these proteins function and perhaps protect the associated cellular compartments from damage via abnormal protein interactions. This could also be inferred from the findings that inhibition of GRPs expression in vitro retards cell growth and lowers its viability after ionophore exposure[21], and the preinduction of GRPs can enhance the tolerance of cells to stress stimuli[22]. In present study, the observed fact that the poorly differentiated colorectal carcinoma Clone A cells can synthesize more Grp94 is understandable from the above reasoning and this experimental system may be used to study the correlation between Grp94 gene expression and tumor growth.

The molecular mechanism involved in the change of Grp94 gene expression during the SB treatment of Clone A cells is unclear. But it has been clarified that, like heat shock genes, promoter region of Grp94 gene contains a short, highly conserved sequence, the heat shock element (HSE), implying that the heat shock factors (HSF) may also be the key transcription factors in the regulation of Grp94 gene expression[23]. In addition, the precise molecular mechanism that mediates SB growth inhibition is also poorly understood. But it is known that SB can cause predominantly a histone $\mathrm{H} 4$ hyperacetylation through inhibition of the histone deacetylase enzyme, allowing the accessibility of transcription factor to turn on specific gene(s), such as $\mathrm{p} 21$ gene, which is a tumor suppressor gene and also a cell-cycle suppressor[24],[25]. But how to account for the down-regulation of Grp94 gene expression after treatment with SB? Can alteration of certain gene(s) directly suppress Grp94 gene via histone hyperacetylation? Or alteration of certain molecular events that can indirectly suppress Grp94 gene via the process of differentiation and maturation in induced Clone A cells? All these problems need further studies.

\section{ACKNOWLEDGMENTS}

This work as a major project was supported by the grants from National Natural Science Foundation (No: 39040005)

\section{REFERENCES}

[1] Subjeck J, Shyy T. Stress proteins systems of mammalian cells. Am J Physiol 1986; 250(1 Pt 1):C1- 
Grp94 expression in colorectal carcinoma cells

17.

[2] Lindquist S. Craig EA. The heat-shock proteins. Annu Rev Genet 1988; 22:631-77.

[3] Schlesinger MJ. Heat shock proteins: the search for functions. J Cell Biol 1986; 103(2):321-5.

[4] Yufu Y, Nishimura J, Takahira H, Ideguchi H, Nawata H. Down-regulation of a Mr 90,000 heat shock cognate protein during granulocytic differentiation in HL-60 human leukemia cells. Cancer Res 1989; 49(9):2405-8.

[5] Yufu Y, Nishimura J, Nawata H. High constitutive expression of heat shock protein 90 in human acute leukemia cells. Leukemia Research 1992; 16(6/7):597-605.

[6] Mileo AM, Fanuele M, Battaglia F, Scambia G, Benedetti PP, Mancuso S, Ferrini U. Selective overexpression of mRNA coding for $90 \mathrm{kDa}$ stress-protein in human ovarian cancer. Anticancer Res 1990; 10(4):903-6.

[7] Singh MK, Yu J. Accumulation of a heat shock-like protein during differentiation of human erythroid cell line K562. Nature 1984; 309 (5969):631-3.

[8] Mivechi NF, Park YK, Hahn GM. Selective expression of heat shock genes during differentiation of human myeloid leukemic cells. Leukemia Research 1994; 18(8):597-608.

[9] Bermejo LG, Vilaboa NE, Perez C, Blas E, Calle C, Aller P. Modulation of hsp70 and hsp27 gene expression by the differentiation inducer sodium butyrate in U-937 human promonocytic leukemia cells. Leukemia Research 1995; 19(10):713-8.

[10] Welch WJ. Mammalian stress response: cell physiology structure /function of stress proteins, and implications for medicine and disease. Physiol Rev 1992; 72:1063-81.

[11] Black AR, Subjeck JR. The biology and physiology of the heat shock and glucose-regulated stress protein systems. Methods Achiev Exp Pathol 1991; 15:126-66.

[12] Lee AS. Mammalian stress response: Induction of the glucose regulated protein family. Curr Opin Cell Biol 1992; 4(2):267-73.

[13] Cai JW, Henderson BW, Shen JW, Subjeck JR. Induction of glucose regulated proteins during growth of a murine tumor. J Cell Physiol 1993; 154 (2):229-37.

[14] Csermely P, Schnaider T, Soti C, Prohaszka Z, Nardai G. The 90-kDa molecular chaperone family: structure, function, and clinical applications. A comprehensive review. Pharmacol Ther 1998; 79 (2): 129-68.

[15] Barnard JA, Warwick G. Butyrate rapidly induces growth inhibition and differentiation in HT-29 cells. Cell Growth Differ 1993; 4(6):495-501.

[16] Wang DS, Lin ZH, Yan YX, He DC, Lei SJ, Zhang QH, Wang KR. The biological effects of sodium butyrate on cultured human stomach cancer cells and esophagenal cancer cells. Acta Biologiae Experimentalis Sinica (in Chinese) 1985; 18(2):189-200.

[17] Ai ZW, Cha XL, Tang H, Chen HL. The reversal effect of retinoic acid on some phenotype of human hepatoma cells. Chinese Journal of Oncology (in Chinese) 1991; 13(1):9-11.

[18] Wang HM, Wang YQ, Song JD. Change of Endoplamic Reticulum in differentiated human colorectal cancer cells induced by retinoic acid. Chinese $J$ of Physical Medcine (in Chinese) 1996; 18(3):150-2.

[19] Bermejo LG, Vilaboa NE, Aller P. Modulation of heat-shock protein 70 (HSP70) gene expression by sodium butyrate in U-937 promonocytic cells: relationships with differentiation and apoptosis. Exp Cell Res 1997; 236(1):268-74.

[20] Srivastava PK, Old LJ. Identification of a human homologue of the murine tumor rejection antigen GP96. Cancer Res 1989; 49(6):1341-3.

[21] Li XA, Lee AS. Competitive inhibition of a set of endoplasmic reticulum protein genes ( Grp78, Grp94, and ERp72) retards cell growth and lowers viability after ionophore treatment. Mol Cell Biol 1991; 11 (7):3446-53.

[22] Cai Shen J, Henderson B, Subjeck J. Analysis of proteins in small and large tumors regard to resistance. Presented at the Cold Spring Harbor Conference, "Stress Proteins and the Heat Shock Response," Cold Spring Harbor, New York, 1991. 
$\mathrm{Wu}$ YD, JD Song

[23] Kohno K, Normington K, Sambrook J, Gething MJ, Mori K. The promoter region of the yeast Kar2 (BIP) gene contains a regulatory domain that responds to the presence of unfolded proteins in the endoplasmic reticulum. Mol Cell Biol 1993; 13:877.

[24] Sonia YA, Shufen M, Amy S, Richard AH. p21WAF1 is required for butyrate-mediated growth inhibition of human colon cancer cells. Proc Natl Acad Sci 1998; 95(12):6791-6.

[25] Archer S, Meng S, Wu J, Johnson J, Tang R, Hodin R. Butyrate inhibits colon carcinoma cell growth through two distinct pathways. Surgery 1998; 124(2):248-53.

Received Feb-23-2000. Revised April-6-2000. Accepted April-7-2000. 